\title{
Photovoltaic Generation Model for Power System Transient Stability Analysis
}

\author{
Linan Qu, Dawei Zhao, Tao Shi, Ning Chen, and Jie Ding
}

\begin{abstract}
It is necessary to model photovoltaic generation system based power system electromechanical transient time scales for large-scale PV connected to power system stability analysis. The model should reflect the non-linear output characteristics, fault ride-through response characteristics and output limits of photovoltaic generation system. A PV model used to meet these demands is proposed in this paper. Base on a 3-generator, 9-bus power system, the comparison and verification of the model is carried out in both DIgSILENT/PowerFactory and PSASP simulation environment.
\end{abstract}

Index Terms-PV model, DIgSILENT/PowerFactory, PSASP, transient stability analysis.

\section{INTRODUCTION}

With the deepening of energy crisis, the development and utilization of solar power generation has got more widespread concern, many countries are increasing efforts to support the development of solar power actively. At the end of 2011, installed capacity of grid-connect photovoltaic (PV) generation has reached $2800 \mathrm{MW}$ in China, and it is expected that the installed capacity will reach $20 \sim 50 \mathrm{GW}$ by the end of 2020. Due to the intermittence and fluctuation of PV generation, the negative impact of large-scale PV generation connecting will be apparent for planning, stability analysis, operation and protection setting of power system. Therefore, to establish PV model, which is suitable for grid-connected PV planning and simulation calculation, has a very important significance, and it provides a platform for large-scale PV connected to power system security, reliability analysis evaluation.

Detail of PV generation, including PV array, inverter, MPPT controller and grid-connected controller, has been modeled in MATLAB/Simulink [1]. Through the PSASP's user program interface function, the PV model participates in transient stability analysis as a current source, to CEPRI 36-node system, for example. Based on electromagnetic transient software PSCAD/EMTDC, the model of PV power system detailed to the power electronic components is established [2]. To establish a PV generation model is used to analysis voltage stability of distribution system containing $\mathrm{PV}$ power stations, that is achieved in MATLAB/Simulink

Manuscript received October 20, 2012; revised November 29, 2012. This work was supported by Nation High Technology R\&D Program of China (no.2011AA05A104) funded by Ministry of Science and Technology, and Science and technology project of State Grid Corporation of China (SG11022).

The authors are with China Electric Power Research Institute, Nanjing 210003, Jiangsu Province, P.R.China. (email: qulinan@epri.sgcc.com.cn, zhaodawei@epri.sgcc.com.cn).
[3]. All the models above are helpful to study the operating characteristics of PV generation. However, for security and stability analysis of large-scale PV generation grid-connected, model of different time scales is needed, to study the impact of PV generation system electromechanical transient response.

In the paper, a PV generation model is established in DIgSILENT/PowerFactory and PSASP (Power System Analysis Software Package, developed by China EPRI). The model can reflect the non-linear output characteristics, fault ride-through response characteristics and output limits of photovoltaic generation. The transient response characteristics of PV model is compared in this two simulation environment.

\section{Photovoltaic Generation Model}

Typically, grid-connected photovoltaic generation system includes PV array, inverter and its controller and conventional power equipment, etc [4]-[7]. PV array converts light energy from the sun into DC electrical energy, and PV inverter, converting direct currents to alternating current, is interfaced with power system via combiner boxes and step-up transformer.

The static generator is an easy-to-use model of any kind of static (no rotating) generator, applying as photovoltaic generators, storage devices, HVDC terminals, and so on [8]. The PV generation system is modeled through the static generator block, shown at the right side of Fig.1, and the PV inverter adopts $U_{d c}-Q$ control strategy. In Fig.1, photovoltaic array model is described PV array; dc capacitor is modeled as DC bus and capacitor and it is shown in Fig.2; Udc controller model is the most important part of the whole PV generation model, providing output current reference values $i_{d_{-} \text {ref }}$ and $i_{q_{-} r e f}$, and it is presented with more detail in Fig.3; PLL model provides the utility voltage angle for static generator.

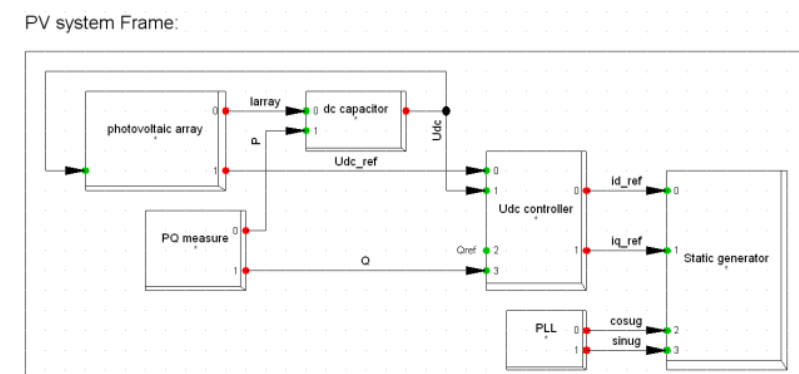

Fig. 1. Frame of PV System in DIgSILENT/PowerFactory

Compared to the actual operation of inverter controller, the model simplifies to the following:

1) The MPPT dynamic process is ignored, and photovoltaic 
array model provides reference values for Udc controller, namely $U_{d c_{-} r e f}=U_{m}$;

2) The response speed of inverter inner loop controller is so fast that the adjustment process is ignored in electromechanical transient simulation, and the following equation is used:

$i_{a c}=\left(i_{d_{-} r e f} \cos u_{g}-i_{q_{-} r e f} \sin u_{g}\right)+j\left(i_{d_{-} r e f} \sin u_{g}+i_{q_{-} r e f} \cos u_{g}\right)$

where, $i_{a c}$ is the output current of PV generation, and $u_{g}$ is the utility voltage angle.

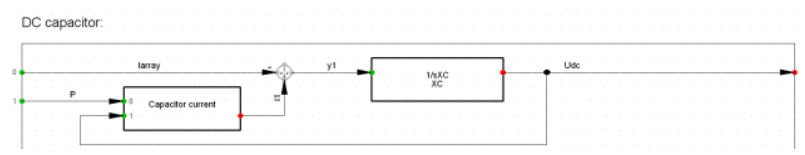

Fig. 2. DC capacitor model

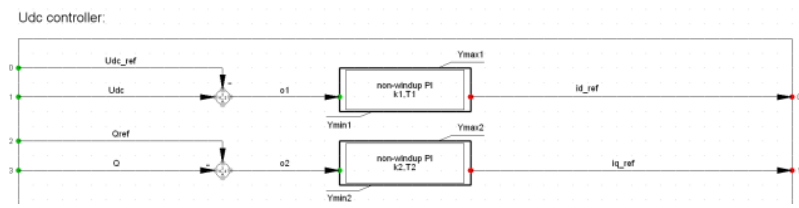

Fig. 3. $U_{d c}-\mathrm{Q}$ controller model

\section{Simulation Results}

PSASP is a widely used power system analysis program in China. A model is developed in PSASP/UD (User Definition), which has the same structure and parameters with the model in DIgSILENT/PowerFactory. Then, different disturbances are set to compare models in the two simulation environment.

The IEEE 3-generator, 9-bus system is investigated, and the PV generation system is connected to power system by booster station, as shown in Fig. 4. Steady-state operation data of PV generation are listed in Table I. Computing PV generation by per unit value (p.u.), PV generation rated power capacity is selected as reference capacity, the maximum power point voltage of PV array under standard conditions is selected as DC reference voltage, and rated AC voltage of PV inverter is selected as AC reference voltage. Characteristic parameters of PV array are listed in Table II.

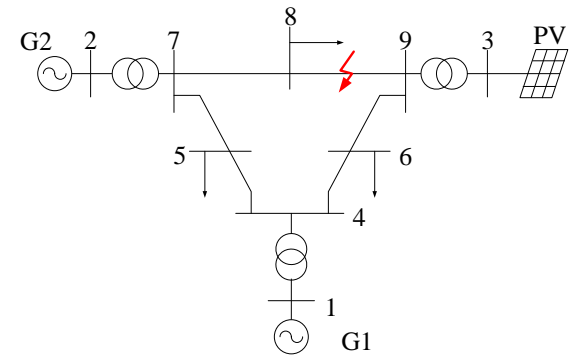

Fig. 4. One-line diagram of the studied power system

TABLE I: STEADY-STATE OPERATION DATA OF PV GENERATION

\begin{tabular}{cc}
\hline \hline PV Generation Operation Data \\
\hline$u_{g}(\mathrm{kV})$ & 13.8 \\
$S_{N}(\mathrm{MVA})$ & 128 \\
$P(\mathrm{MW})$ & 85 \\
$Q(\mathrm{MVar})$ & 10.9 \\
$\mathrm{~S}\left(\mathrm{~W} / \mathrm{m}^{2}\right)$ & 701.74 \\
$\mathrm{~T}\left({ }^{\circ} \mathrm{C}\right)$ & 25 \\
\hline \hline
\end{tabular}

TABLE II: CHARACTERISTIC PARAMETERS OF PV ARRAY [10]

\begin{tabular}{cc}
\hline \multicolumn{2}{c}{ PV Array } \\
\hline$U m$ (p.u.) & 1 \\
$I_{m}$ (p.u.) & 1 \\
$U o c$ (p.u.) & 1.254 \\
$I_{S C}$ (p.u.) & 1.0715 \\
\hline \hline
\end{tabular}

\section{A. Simulation Results in Case of Power System Fault}

A pure three-phase short circuit is simulated on the middle of line between node 8 and node 9 , and the short circuit is cleared after $0.1 \mathrm{~s}$. The comparison between DIgSILENT/PowerFactory and PSASP under this fault is described in Fig. 5.

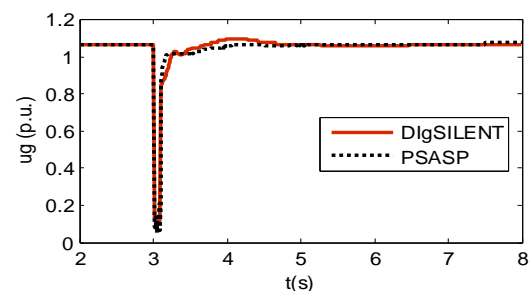

(a) grid-connected voltage

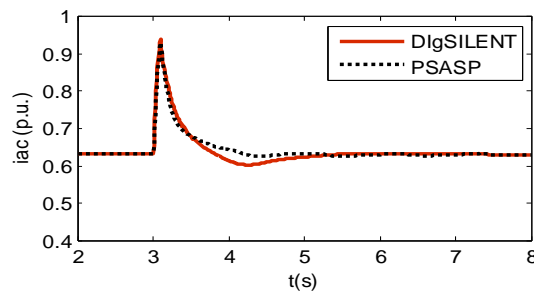

(b) output current

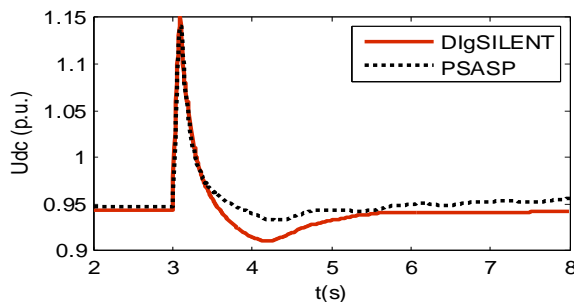

(c) voltage of DC bus

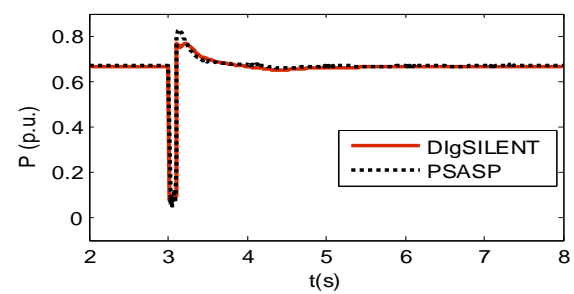

(d) active power

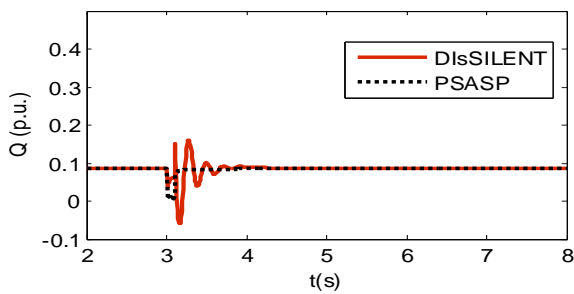

(e) reactive power

Fig. 5. A comparison of PV response characteristics between PSASP and DIgSILENT/PowerFactory under fault

PV generation relative calculation results of DIgSILENT/PowerFactory and PSASP are consistent in failure free operation. Transient process (the voltage dips in 
PV generation grid-connected point caused by the short circuit, until the PV output current achieves stable):

1) The voltage dip depth and recovery curve of PV generation grid-connected point is basically as the same.

2) During transient process, output current, active power and DC voltage of PV generation is also basically as the same.

3) In the period of the utility voltage recovery, reactive power injected from the PV generation fluctuates in DIgSILENT/PowerFactory, but the process is not obvious in PSASP. The reason for the difference may be that static generator active power and reactive algorithm is not completely decoupled.

\section{B. Cloudiness Disturbance}

When cloud blocks sun, the irradiation suddenly reduces to $301.74 \mathrm{~W} / \mathrm{m}^{2}$, sustaining $2 \mathrm{~s}$. The comparison between DIgSILENT/PowerFactory and PSASP under this disturbance is described in Fig. 6.

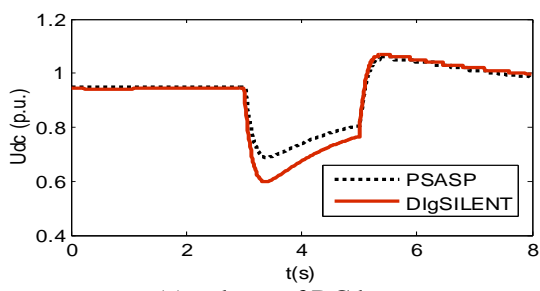

(a) voltage of DC bus

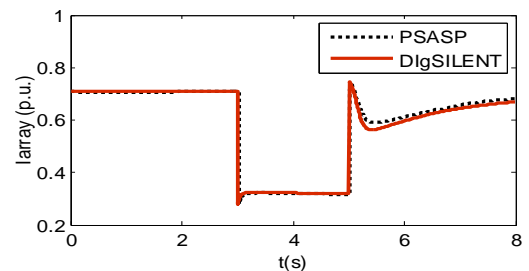

(b) PV array current

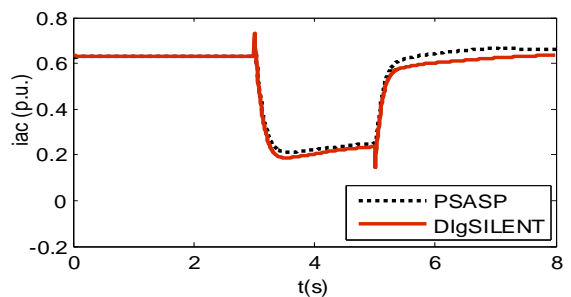

(c) output current

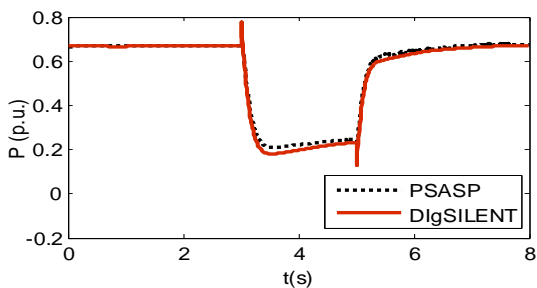

(d) active power

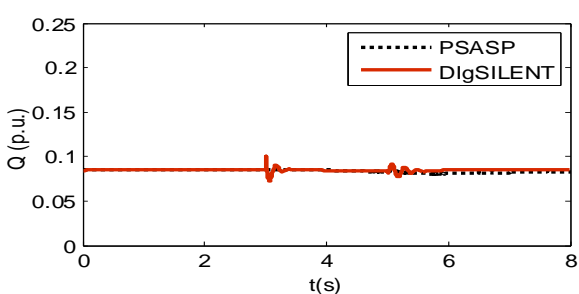

(e) reactive power

Fig. 6. A comparison of PV response characteristics between PSASP and DIgSILENT/PowerFactory under cloudiness disturbance
PV generation relative calculation results of DIgSILENT/PowerFactory and PSASP are consistent in both steady-state operation and cloudiness disturbance process.

\section{CONLUSIONS}

A photovoltaic generation system model is established based power system electromechanical transient time scale, and is developed respectively in the DIgSILENT/PowerFactory and PSASP. Transient responses of photovoltaic generation, including active power, reactive power, output current, DC voltage of PV generation, and voltage in PV generation grid-connected point, are compared and basically as the same.

\section{REFERENCES}

[1] W. Zhang, T.-Y. Xiang, A. Li et al., "Matlab-Psasp based transient stability computation model for grid-connection of PV power system," Electric Power Automation Equipment, vol. 23, no. 6, pp. 80-85, June 2012.

[2] C.-J. Fan and Y. Peng, "Modeling of Photovoltaic Generation System Based on PSCAD," Research and Exploration in Laboratory, vol. 31 , no. 1, pp. 35-38, Jan. 2012.

[3] X.-Y. Deng, "Photovoltaic Station Modeling and Studies on Voltage Stability of Regional Grid-Connected Photovoltaic Station," M.S thesis, Dept Elect. Eng., Xinjiang University, China, May 2011.

[4] N. P. Papanikolaou, E. C. Tatakis, and A. C. Kyritsis, "Analytical Model for PV - Distributed Generators, suit able for Power System Studies," Power Electronics and Applications, Sept. 2009.

[5] N.-Y. Li, J. Liang, and Y.-S. Zhao, "Research on Dynamic Modeling and Stability of Grid-connected Photovoltaic Power Station," in Proc. of CSEE, vol. 31, no. 10, pp. 12-18, Apr. 2011

[6] Á. Ruiz, "System aspects of large implementation of a photovoltaic power plant," M.S. thesis, Dept. Electron. Eng., Kungliga Tekniska Högskolan, 2011.

[7] D.-R. Liu, S.-Y. Chen, M. A. Min et al., "A Review on Models for Photovoltaic Generation System," Power System Technology, vol. 35 , no. 8, pp. 47-52, Aug. 2011.

[8] DIgSILENT PowerFactory. [Online]. Available: http://www.digsilent.de

[9] J. Selvaraj and N. A. Rahim, "Multilevel Inverter For Grid-Connected PV System Employing Digital PI Controller," IEEE Transactions on Industrial Electronics, vol. 56, pp. 149-158, 2009.

[10] Yingli Energy. [Online]. Available: http://www.yinglienergy.com

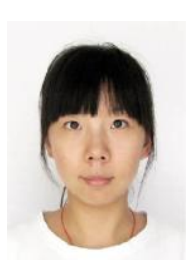

Linan Qu was born on December 18, 1985, in Hebei, China. She received the M. S. degree from Harbin Institute of Technology, China in 2010, and she is currently an R\&D engineer in China Electric Power Research Institute. Her current research interests include photovoltaic gird-connected analysis and PV system modeling.

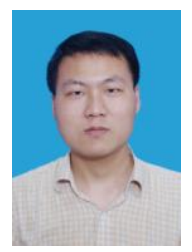

Dawei Zhao was born on October 28, 1981, in Henan, China. He received the M. S. degree from Southeast University, China in 2006, and he is currently an R\&D engineer in China Electric Power Research Institute. His current research interests include new energy grid integration, excitation system and subsynchronous resonance (SSR) .

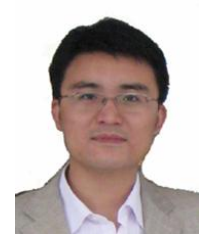

Tao Shi received the B.E. degree in 2005 and M.E degree in 2007 , and he is currently an electrical engineer at China Electric Power Research Institute in Nanjing, China.His research interests include power system analysis and photovoltaic generation modeling. 


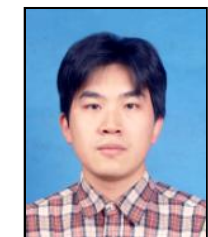

Ning Chen received the B.E. degree in 2005 and M.E

degree in 2007 from Harbin Institute of Technology,

China. He is currently an electrical engineer at China

Electric Power Research Institute in Nanjing, China. His

research interests include power system analysis and

development of operation control technology for new generation grid integration.

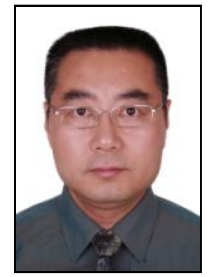

Jie Ding received the Master's degree from Southeast University. He is mainly engaged in new energy power grid, detection technology, new energy and conventional energy joint scheduling technology and other aspects of the research. 